\section{Histerectomía vaginal guiada por visualización laparoscópica}

La histerectomía laparoscópica fue descrita por primera vez por Reich en 1989. La mayor parte de la cirugía se hace por visualización con el laparoscopio, pero la ligadura de las arterias uterinas se hace por vía vaginal. Aunque muchos autores han descrito el uso de esta técnica, la mayor parte de los trabajos publicados representan experiencias individuales o de grupos pequeños con un adiestramiento técnico especial. Dadas las claras virtudes del procedimiento, actualmente poco difundido en los países de América Latina y el Caribe, un grupo de investigadores costarricenses ha revelado los resultados de las primeras 30 histerectomías vaginales efectuadas en Costa Rica con la ayuda de visualización laparoscópica.

Todas las histerectomías se realizaron en un período de 19 meses y se evaluaron desde el punto de vista de la recuperación de la paciente. La anestesia fue general en todos los casos, sin que se presentara ninguna complicación, y el tiempo operatorio fue de 122 minutos en promedio. La estancia hospitalaria media fue de 38,3 horas tras un período de preparación preoperatoria de 4 horas.

Durante la cirugía se presentaron dos casos de complicaciones por ruptura de vejiga. En el primero fue necesario cambiar de vía de acceso y en el segundo se continuó por la misma después de suturar la vejiga. Ninguna paciente necesitó una transfusión de sangre y todas volvieron a su actividad normal en un plazo máximo de 8 días. Dos pacientes que tuvieron hemorragia cíclica al mes de la operación fueron sometidas a morselación del endocérvix con fines preventivos.

En conclusión, la histerectomía vaginal asistida por visualización laparoscópica puede practicarse con riesgos mínimos en hospitales privados que estén provistos del instrumental apropiado y de cirujanos adecuadamente preparados y acreditados en el uso de la técnica. Se considera un procedimiento beneficioso para la paciente, ya que el tiempo de recuperación es breve y la reincorporación a las actividades cotidianas, más rápida que cuando se aplican otras técnicas. Esto no implica, sin embargo, que todas las histerectomías deban ser vaginales; se calcula que aproximadamente 30\% seguirán haciéndose por la vía abdominal. La experiencia y el buen sentido del cirujano determinarán el mejor método para un caso determinado. (Mangel León T, et al. Histerectomía vaginal asistida por video laparoscopía (HVAVL): primeras experiencias en Costa Rica. Rev Centroamericana Ginecol Obstet 1996;6:92-97.)

\section{El edema de miembros inferiores: causas y medidas que lo alivian}

La hinchazón de las piernas, que puede afectar a cualquier persona si permanece de pie por mucho tiempo, obedece a un desequilibrio del intercambio normal de líquidos entre el espacio intracapilar e intersticial en los miembros inferiores. Este intercambio es el resultado de dos presiones que actúan en dirección contraria: la hidrostática y la oncótica. La primera, que es intravascular, empuja el líquido contra las paredes finas de los capilares; la segunda lo atrae hacia el espacio intracapilar.

Varias causas, algunas peligrosas, alteran este mecanismo de intercambio de líquidos. Entre las más benignas se encuentran las várices, o insuficiencia de las válvulas que impulsan la sangre hacia el corazón. Al acumularse la sangre en las piernas, la presión hidrostática dentro del lecho capilar aumenta hasta tal grado que supera la presión oncótica, y ello obliga al líquido a salir por las paredes de los capilares y a acumularse en los tejidos intersticiales.

También puede producirse un exceso de presión hidrostática por insuficiencia cardíaca congestiva, que es la causa más frecuente de hinchazón de las piernas. En este caso, la sangre se estanca en los miembros inferiores porque el corazón no tiene fuerza para impulsarla adecuadamente. Otra causa frecuente de hinchazón de miembros inferiores es la reducción de la presión oncótica por hipoalbuminemia de origen nutricional, hepático, renal o intestinal. Sin la acción hidrofílica de la albúmina, el líquido intravascular se escapa hacia el espacio intersticial. La obstrucción de los vasos linfáticos debido a inflamación local, la presencia de tejido cicatrizal y la compresión local por un tumor también pueden dar origen a hinchazón de las piernas y de los tobillos. Por último, cualquier persona puede sufrir un aumento transitorio de la permeabilidad vascular por alergias, quemaduras, picaduras de insecto, o infecciones bacterianas. 
Independientemente de la causa, ciertas medidas sencillas pueden mejorar el problema. La elevación de los pies con almohadas durante la noche y varias veces al día a una altura de $30 \mathrm{a} 40 \mathrm{~cm}$ por encima de la cabeza proporciona alivio. También se recomienda usar medias gruesas especiales desde la mañana para no dar oportunidad a que las piernas se hinchen. Otras prácticas beneficiosas son el ejercicio diario, la pérdida de peso y un bajo consumo de sal. Si estas medidas no dan resultados, se puede considerar el uso de un diurético prescrito por un médico. En raras ocasiones, el edema de las piernas acompañado de rubor y calor locales o de dificultad respiratoria puede ser señal de infección o de un trastorno cardíaco o pulmonar urgente y en estos casos es imprescindible acudir a un médico. (Smoots ES. Peripheral edema: drying out waterlogged legs. Harvard Health Letter 1997;22:6-7.)

\section{Un llamado para poner fin a la mutilación genital femenina}

Las autoridades de tres agencias de las Naciones Unidas se han dirigido a la comunidad internacional y a sus líderes solicitando su apoyo a los esfuerzos tendientes a eliminar la mutilación genital femenina (MGF). Con ese fin, Hiroshi Nakajima de la OMS, Carol Bellamy del Fondo de las Naciones Unidas para la Infancia y Nafis Sadik del Fondo de Población de las Naciones Unidas presentaron un plan orientado a lograr la mayor declinación posible de la MGF en 10 años y su completa desaparición en el curso de tres generaciones. La eliminación de una práctica tan riesgosa como injustificable ha de acompañarse de una considerable mejoría en la salud de millones de mujeres y niñas del tercer mundo, particularmente en los países africanos. A la vez, representará una importante contribución a la promoción de los derechos humanos y de la igualdad entre los sexos. Las tres agencias hacen hincapié en la conveniencia de un abordaje multidisciplinario para la constitución de equipos allí donde se practique la MGF; esos equipos, aunque financieramente sostenidos por las organizaciones internacionales, actuarán en coordinación con las entidades gubernamentales y con las asociaciones políticas y religiosas en cada país. Según el acuerdo establecido entre las tres agencias, también se asistirá a los gobiernos para la implementación de políticas nacionales que explícitamente promuevan la abolición de la MFG y, cuando así lo requieran las circunstancias, legislen su prohibición. Los equipos de trabajo centrarán sus esfuerzos en un intento por cambiar la opinión pública en aquellos países donde la práctica es tradicional, y para ello recurrirán a la población en general, a los profesionales de la medicina y a los líderes gubernamentales, políticos y religiosos, para así poder difundir una mayor información acerca de los daños físicos y psicológicos provocados por la MGF.

En ocasiones también definida como circuncisión femenina o excisión, la MGF es habitualmente realizada por personas que tradicionalmente tienen a su cargo esa función, recurriendo para ello a cuchillos, navajas y trozos de vidrio, y omitiendo la anestesia. Solo en el caso de los sectores más prósperos de la sociedad, la intervención es efectuada por personal profesional calificado. La edad a la que se practica varía según el lugar, pero usualmente se lleva a cabo en niñas de 4 a 12 años.

Las repercusiones que puede tener la MGF sobre la salud dependen del tipo de procedimiento empleado, de la destreza de quien la practica y de las condiciones higiénicas tanto de los instrumentos como del ambiente en que se efectúa. A menudo ocurren complicaciones a breve plazo, como dolor, choque, hemorragia, retención de orina, ulceración de la región genital y lesión de los tejidos adyacentes; las que aparecen a largo término corresponden a quistes y abscesos, formación de cicatriz queloide, daño uretral seguido de incontinencia urinaria, dispareunia, disfunción sexual, infección del tracto urinario, esterilidad y parto distócico.

Hoy en día, el número de niñas y mujeres que han sido sometidas a la MGF se estima en más de 130 millones, a los que deben sumarse alrededor de 2 millones de niñas que cada año estarán expuestas a ese riesgo. La mayoría de las afectadas viven en 28 países africanos, en tanto que el resto está disperso en Asia y el Oriente Medio. Los casos que se observan en Australia, Canadá , Estados Unidos de América y Europa corresponden a inmigrantes de los países en que la práctica es tradicional. (World Health Organization. UN agencies call for end to female genital mutilation. Comunicado de prensa WHO/29, 9 de abril de 1997.)

\section{Dos organismos internacionales aúnan esfuerzos para combatir la malaria}

Sobre la base del papel que puede desempeñar la educación en la prevención de la malaria, el pasado 2 de mayo Hirashi Nakajima, Director General de la OMS, y Federico Mayor, Director General de la Organización de las Naciones Unidas para la Educación, la Ciencia y la Cultura (UNESCO) firmaron un memorándum acordando la colaboración de ambas organizaciones en la asistencia a países que requieran implementar la Estrategia para el Control Global de la Malaria. Cada año de 300 a 500 millones de personas enferman de malaria y de 1,5 a 2,7 millones mueren por esa enfermedad; de esas 
defunciones, alrededor de 90\% ocurren en el África subsahariana.

Como la malaria es prevenible y curable, la OMS y la UNESCO han de ejercer su acción a través de la educación sanitaria, recurriendo para ello a la movilización de escolares, de sus padres y también de la comunidad en general, a fin de promover una conducta fundamentada en medidas de prevención personal, diagnóstico y tratamiento tempranos, y en medidas sanitarias apropiadas. Así será posible lograr una reducción sustancial de las tasas de mortalidad en niños pequeños y de la morbilidad en escolares. Según los términos del memorándum, ambas organizaciones colaborarán en la educación y protección de los niños mediante la preparación de materiales didácticos, el adiestramiento de maestros y de todo personal relacionado con la enseñanza, y la elaboración de comunicados para su difusión por medios más adecuados. El memorándum es parte de los esfuerzos que la OMS está realizando para implementar la Estrategia para el Control Global de la Malaria en conjunción con los ministerios de salud de cada país.

Los estudios que la UNESCO llevó a cabo en el África rural mostraron que más de un sexto de los niños que asisten a la escuela primaria sufren dos o más accesos de malaria en el curso de un año lectivo, y eso representa un ausentismo de una semana o más por cada acceso. Es evidente que la colaboración acordada entre la OMS y la UNESCO ha de permitir una mejor educación para esos niños, ya que no será interrumpida por enfermedad. Y a largo plazo, es indudable que una mayor continuidad en la educación favorecerá un deseable desarrollo social y económico. (World Health Organization. WHO, UNESCO join together to fight malaria. Comunicado de prensa $\mathrm{WHO} / 38,7$ de mayo de 1997).

\section{Reconsideración de los riesgos asociados con la enfermedad de Creutzfeldt-Jakob}

Del 24 al 26 de marzo de 1997 y en una reunión organizada a ese efecto, los expertos de la OMS coincidieron en la necesidad de efectuar una revisión de los conceptos vigentes acerca de las encefalopatías espongiformes transmisibles y de establecer normas de seguridad para los productos medicinales de origen animal y humano, particularmente en referencia a la sangre y sus fracciones. En el curso de la reunión se brindó información reciente y fundamentada por estudios de transmisión experimental y datos epidemiológicos. Así, Paul Brown, de los Institutos Nacionales de Salud, Bethesda, Estados Unidos de América, presentó resultados sugerentes de la presencia de infectividad en la sangre, sea entera o fraccionada. Hasta ahora, esos materiales se han considerado carentes de riesgo, ya que no existían pruebas de transmisión de la enfermedad de Creutzfeldt-Jakob (CJ) por transfusión de sangre o de hemoderivados. Sin embargo, Brown ha demostrado que fracciones plasmáticas obtenidas de ratones adaptados a la infección por CJ humana son capaces de transmitir la enfermedad después de su inoculación intracerebral en ratones sanos. Estos datos, a esa fecha todavía no publicados, en rigor confirman una anterior referencia a CJ humana transmitida a partir de glóbulos blancos y de sangre entera. Si bien Brown advirtió que no era conveniente extrapolar los resultados de estudios experimentales en animales a casos clínicos en humanos, de igual forma sugirió que el plasma, y sobre todo su crioprecipitado, podrían representar una amenaza hasta ahora no considerada.

La OMS ha recomendado que los criterios de selección de donantes de sangre excluyan a las personas con riesgo de CJ y de otras encefalopatías espongiformes transmisibles, es decir, todas las que registren antecedentes familiares de esas enfermedades y también aquellas que alguna vez hayan recibido extractos de hipófisis humana (hormona de crecimiento y gonadotropina) o injertos de duramadre humana. Aunque esas recomendaciones concuerdan con normas ya en práctica en muchos países, su aplicación puede causar algunos problemas logísticos. Al respecto, cabe debatir si sería realmente efectivo excluir a todas las personas que en los pasados 10 años recibieron injertos de duramadre, cuando en rigor muchos de los pacientes sometidos a intervenciones neuroquirúrgicas ignoran ese detalle y por lo tanto no lo pueden aportar en el interrogatorio.

Pero existe una preocupación más acuciante suscitada por las posibles pruebas de una vinculación entre la encefalopatía espongiforme bovina y la nueva variante de CJ. Si ese fuera el caso, todas las reservas de sangre en el Reino Unido presentarían condiciones de riesgo, incluidos algunos productos plasmáticos tan difundidos como la inmunoglobulina. Pero como bien expresó el encargado del Servicio de Transfusión de Sangre del Reino Unido, hay que tener presente que el agente causal de la CJ clásica y su nueva variante pueden comportarse de forma muy diferente entre sí.

La reunión concluyó con un acuerdo unánime sobre la necesidad de continuar haciendo estudios sobre el tema. Por su parte, Brown está planeando experimentos para evaluar métodos que permitan la remoción de contaminantes celulares del plasma que inhibirían la detección de su infectividad. En cuanto a disposiciones ya adoptadas por organismos del Reino Unido, es de destacar la asignación de $£ 8$ millones para el desarrollo de investigaciones 
sobre las encefalopatías espongiformes transmisibles. (Morris K. WHO reconsiders risks from Creutzfeldt-Jakob disease. Lancet 1997;349:1001).

\section{Hacia un consenso internacional para el empleo de terapia antirretroviral}

Solo recientemente ha podido disponerse de técnicas de laboratorio lo suficientemente sensibles para confirmar el carácter dinámico de los virus de la inmunodeficiencia humana (VIH) en todas las etapas de la infección. Es ahora evidente que la destrucción de las células CD4 es resultado de la replicación viral. En un determinado punto crítico, comúnmente después de varios años de infección, la homeostasis entre la replicación de VIH y la producción de células CD4 ya no puede mantenerse por más tiempo y sobrevienen entonces la declinación del recuento celular y la aparición de enfermedad. La tasa de replicación viral puede hoy ser estimada por la carga viral en el plasma, que hasta ahora es el mejor indicador de la progresión hacia el sida o la muerte.

Ya existen estudios suficientemente completados para demostrar concluyentemente que el uso de una terapia combinada puede conducir a una sobrevida aceptable. De hecho, la potencia cada vez mayor de los antivirales ha logrado mejorías clínicas estimables. Como consecuencia, ha emergido un consenso internacional en cuanto a los lineamientos que deben seguirse en la aplicación de la terapia antirretroviral. Pese a discrepancias menores, las coincidencias son las predominantes. Ello es atribuible a la aceptación de cinco principios terapéuticos incuestionables: monitoreo de la carga viral en plasma y del recuento de células CD4; institución del tratamiento antes de que la inmunodeficiencia se manifieste; reducción de la carga vírica durante el mayor tiempo posible; combinación de por lo menos dos fármacos, con fines de lograr el máximo efecto antiviral y de reducir a un mínimo la resistencia cruzada y la toxicidad, y sustitución de un esquema terapéutico por otro, en caso de que la carga viral repunte pese a un tratamiento continuado.

Dados los rápidos progresos que se están registrando en la terapia antirretroviral, es previsible que los lineamientos terapéuticos deban ser periódicamente revisados, aunque a la fecha y teniendo en cuenta cuáles son los productos autorizados para su uso, cabe aceptar que el tratamiento debe combinar tres fármacos: dos análogos de nucleósidos y un poderoso inhibidor de la proteasa o un inhibidor no nucleósido de la transcriptasa inversa.

Sin embargo, todavía restan muchas dudas por aclarar, como por ejemplo, cuál sería la etapa de la replicación viral más fácil de interrumpir, cuándo correspondería iniciar el tratamiento, o qué estrategia sería la más apropiada para combinar secuencialmente los diferentes fármacos. A la vez, urge resolver el gran problema representado por el costo de la terapia antirretroviral. Al respecto, la experiencia alcanzada con la tuberculosis indica que, aun disponiendo de medicamentos específicos para erradicar una infección, ese logro no puede alcanzarse si no se facilita el cumplimiento del tratamiento. En consecuencia y en relación a VIH, los esfuerzos para simplificar los esquemas terapéuticos no deben postergarse hasta tanto se puedan precisar las pautas definitivas, ya que ambos objetivos se están alcanzando en forma conjunta. (Montaner JSG, et al. Emerging international consensus for use of antiretroviral therapy. Lancet 1997;349:1042).

\section{Epidemiología y biología de la transmisión sexual del VIH}

La transmisión sexual es la causa de 75 a $85 \%$ de los casi 28 millones de personas infectadas por el VIH. En el nivel poblacional, los tres vértices del clásico triángulo epidemiológico - huésped (susceptibilidad e infecciosidad), ambiente (condiciones culturales, sociales y políticas) y agente etiológico (VIH tipo 1) - determinan la infectividad, o probabilidad promedio de transmisión de una persona a otra. La susceptibilidad del huésped a la infección depende de la entrada del virus a linfocitos T CD4 y macrófagos por adherencia a sus receptores de superficie de quimoquinas. En la mujer, el epitelio glandular alberga el VIH en la zona de transición (de células columnares a células escamosas) del cuello uterino. En el hombre, el virus se detecta en las células y el plasma seminales. La susceptibilidad del huésped puede estar afectada por factores dependientes de la inflamación o la activación inmunitaria, que alterarían el número de células susceptibles o su receptividad. Otros factores producen erosiones microscópicas que permiten el acceso directo del virus al torrente sanguíneo o facilitan la supervivencia viral en mucosas orales, genitales o rectales. Se dispone de datos epidemiológicos que sugieren en algunos una falta de susceptibilidad a la infección, ya que existen hombres y mujeres que no se contagian, pese a reiterados contactos sexuales sin protección con infectados. $\mathrm{Al}$ respecto, se ha identificado una mutación (CKR5) en el gen del receptor de quimoquinas, cuya proporción varía según la raza ( $11 \%$ y 1,7\% de homocigotos en negros y blancos, respectivamente, serían resistentes a la infección). Se sabe que la contagiosidad del infectado depende de la concentración viral 
en el tracto genital, que aumenta cuando desciende el recuento de linfocitos T CD4. Sin embargo, el período de la infección primaria entre la exposición al VIH y la aparición de anticuerpos específicos también puede estar asociado a una elevada infecciosidad. En cambio, la terapia antirretroviral reduce en $50 \%$ la posibilidad de transmisión y retarda la progresión de la enfermedad. Por el contrario, la presencia en el tracto genital de úlceras (chancro blando, lesiones sifilíticas o herpéticas) o infección por Neisseria gonorrhoeae, Chlamydia o Trichomonas, ejerce un efecto potenciador sobre la incidencia e infecciosidad del VIH. Factores menos determinantes pero también favorecedores del ingreso del virus son la ectopia cervical, por provocar friabilidad tisular, y la menstruación o el sangrado durante el coito. En cambio, la circuncisión masculina tendría cierto efecto protector, ya que la presencia de prepucio y consiguientemente de un elevado número de células de Langerhans, proporciona un blanco adecuado para el virus.

En cuanto al entorno ambiental, su acción se ejerce a través de normas sociales que pueden influir sobre la elección o no de prácticas sexuales específicas, de parejas de determinado perfil, de empleo de anticonceptivos, y de uso de sustancias que disminuyan las inhibiciones sexuales. La exposición a factores de riesgo ambiental indica que la vulnerabilidad concomitante a una injusta distribución de recursos sociales y económicos contribuye a la difusión de la epidemia.

Con respecto al agente biológico en sí, también puede influir en la transmisión de la infección. Los subtipos del VIH exhiben diferentes distribuciones geográficas, ya que A, C, D y E predominan en el África subsahariana y en el Asia, en tanto que B lo hace en los Estados Unidos de América, el Caribe, América del Sur y Europa Occidental. El subtipo E, cuyo tropismo por las células de Langerhans es mayor que el del B, es el predominante en Tailandia; es probable que el acentuado tropismo del subtipo E sea responsable de la rápida difusión del virus en ese país y de las elevadas tasas de transmisión que allí se registran.

Las estrategias para prevenir la transmisión sexual del VIH se focalizan en estimular el uso de preservativos, tratar las enfermedades de transmisión sexual, y desalentar las conductas sexuales riesgosas. En combinación, esas tres estrategias inciden en los tres vértices del triángulo epidemiológico. Así, se ha logrado reducir la prevalencia de sida y otras enfermedades de transmisión sexual en Tailandia y Tanzanía, y alcanzar resultados promisorios en Uganda.

Toda intervención tendiente a combatir la epidemia ha de ser más efectiva cuanto más se oriente hacia las etapas tempranas de la infección. Para ello, los pacientes y los médicos deben reconocer los signos tempranos (fiebre, faringitis, adenopatías, exantema y meningitis aséptica), y los laboratoristas disponer de técnicas de amplificación capaces de detectar la infección antes de que ocurra la seroconversión. Una vez identificada la infección primaria, se hace esencial la coordinación entre los departamentos de salud para impedir la transmisión; además, una terapia antirretroviral de institución temprana puede reducir la carga viral, y con ello mejorar el pronóstico y reducir la infecciosidad.

Ya es tiempo de desarrollar e implementar políticas sanitarias sobre la base de la experiencia acumulada en los últimos 15 años. Con un abordaje multidisciplinario, fundamentado en la epidemiología de la infección, la biología del virus y la caracterización sociológica del sector más afectado de la sociedad, cabe esperar una reducción apreciable en la transmisión sexual del VIH. (Royce RA, et al. Sexual transmission of HIV. N Engl J Med 1997; 336:1072-1078).

\section{En búsqueda de un tratamiento para la enfermedad de Alzheimer}

El desarrollo de medicamentos para el tratamiento de la enfermedad de Alzheimer está en sus comienzos. A la fecha y en los Estados Unidos de América, solo dos drogas están aprobadas para su uso (tacrina y donepezil), aun cuando ninguna de ellas actúa sobre los procesos subyacentes responsables de la pérdida de neuronas y de sinapsis que lleva al deterioro intelectual y funcional. Dados el creciente envejecimiento de la población en general y los trágicos efectos de las enfermedades relacionadas con la mayor edad, es comprensible el interés en disponer de tratamientos para la enfermedad de Alzheimer. Entre los más recientes aportes a ese respecto, es de destacar la experiencia de Sano et al. con el uso de selegilina y alfatocoferol (vitamina E); con esos dos medicamentos se pretende retardar la progresión del daño neuronal y, en consecuencia, la aparición de manifestaciones de demencia. Si bien las conclusiones son alentadoras, cabe un interrogante acerca de la real significación de los resultados obtenidos, ya que los mismos autores reconocen el problema planteado por las comparaciones múltiples y la necesidad de apropiados ajustes estadísticos. En muchos aspectos, el estudio es similar al de la terapia antioxidativa a base de deprenil y tocoferol para la enfermedad de Parkinson (Deprenyl and Tocopherol Antioxidative Therapy of Parkinsonism, DATATOP), en cuyo caso se demostró que la selegilina pero no el alfatocoferol 
postergaban significativamente el requerimiento de levodopa en los pacientes con enfermedad de Parkinson. No obstante, esos beneficios no se siguieron observando con el ulterior seguimiento y los autores concluyeron que los efectos percibidos quizás no eran expresión de un retardo en la evolución del proceso de degeneración subyacente.

Cuando se estudian los efectos de drogas que curan una enfermedad o que conllevan beneficios ostensibles, los resultados son fáciles de interpretar. No sucede lo mismo cuando se pretende evaluar tratamientos diseñados para detener la gradual declinación observada en los pacientes con Alzheimer. El conocimiento que hasta ahora se tiene de la enfermedad sugiere que son varios los factores causales y que la secuencia de eventos degenerativos se produce en forma de cascada. Los antioxidantes como el alfatocoferol y la selegilina empleados por Sano et al., e incluso otros más poderosos, podrían tal vez emplearse como parte de estrategias combinadas orientadas a retardar y hasta detener el progreso de la enfermedad de Alzheimer. Otros tratamientos están en consideración: la terapia hormonal sustitutiva, los medicamentos antiinflamatorios y los factores de crecimiento neural. Así como la leucemia puede ser exitosamente tratada mediante el uso combinado de drogas que, empleadas en forma aislada, tienen cierto efecto sobre alguna de las variadas etapas del proceso patológico, también en el de Alzheimer podría ocurrir algo similar. Hasta la fecha, la vitamina E es de venta libre y la selegilina se obtiene por prescripción médica. Pero en su ya citado trabajo, Sano et al. advierten que se impone la prosecución de estudios adicionales para establecer la efectividad real del alfatocoferol y la selegilina en el tratamiento a largo plazo de la enfermedad de Alzheimer. En todo caso, bien vale alentar la continuidad de esas investigaciones, la búsqueda de tratamientos complementarios y el diseño de estrategias combinadas para, por lo menos, lograr una diferencia estimable entre los pacientes medicados y los pacientes controles. (Drachman DA, Leber P. Treatment of Alzheimer's disease: searching for a breakthrough, settling for less. N Engl J Med 1997;336:1245-1247).

\section{Un sistema para evaluar la farmacodependencia en la ciudad de México}

La farmacodependencia no afecta exclusivamente a quien la padece, sino que extiende sus efectos negativos sobre los ámbitos familiar, académico, laboral y comunitario del usuario. De ahí su incidencia directa sobre la salud, la economía y la dinámica social de un país. Como México carece de sis- temas de notificación obligatoria, el Sistema de Reporte de Información sobre Drogas (SRID) ofrece una alternativa útil , sobre todo por su confiabilidad y bajo costo, para aquellos países en vías de desarrollo que disponen de recursos limitados para encarar otro tipo de encuestas.

El Instituto Mexicano de Psiquiatría había establecido su propio sistema de reporte sobre drogas, ante la necesidad de contar con información periódica y homogénea que permitiera el diseño de programas de prevención. Con el fin de su evaluación por el SRID, se recopilaron diversos indicadores, entre ellos los sugeridos por la OMS y los em-pleados por sistemas similares en los Estados Unidos de América, Canadá y Hong Kong, además de los que se consideraron relevantes para el caso de México. Una vez elaborada la base metodológica, en septiembre de 1986 el SRID comenzó a operar en el área metropolitana de México, DF, después de haber concertado la participación de diversas instituciones públicas. Para noviembre de 1995, los perfiles de los consumidores de drogas incluían una mayoría de varones (9:1), primer contacto con la droga entre los 12 y 19 años, y predominio de solteros y de nivel socioeconómico bajo. En general, el motivo más importante del ingreso de usuarios a instituciones de salud fue por solicitud de tratamiento $(73,5 \%)$; en cuanto a organismos judiciales, fue por actos ilícitos $(50,8 \%)$ tales como robos y lesiones. En referencia al tipo de droga consumida, cabe destacar el considerable incremento registrado por la cocaína, ya que valores de 1,6\% en 1986 habían ascendido a 31\% en 1995. Variados son los factores determinantes de este aumento: mayor disponibilidad de la droga en el mercado, consiguiente abaratamiento que la hace accesible para sectores de bajos recursos y también para jóvenes, persistencia en muchos usuarios de la asociación entre cocaína y estatus, y popularización de derivados de todavía menor precio (crack, hoy definido como "droga del pobre").

El establecimiento del SRID en México ha permitido contar con información periódica y actualizada sobre el consumo de drogas durante los últimos 10 años, lo que suministra una base adecuada para la implementación de políticas nacionales en materia de investigación y prevención de la farmacodependencia. Dado que el SRID reconoce que sus resultados son representativos de un grupo específico de la población y por tanto de valor limitado, en la actualidad se está incorporando a instituciones privadas para poder así disponer, se espera que a corto plazo, de los datos correspondientes a ese sector. (Galván-Reyes J, et al. El Sistema de Registro de Información sobre Drogas: un auxiliar diagnóstico en la evaluación de la farmacodependencia. Salud Publica Mex 1997; 39:61-67). 


\section{Reevaluación de la prevalencia de la esquistosomiasis en el Brasil}

Desde su llegada al Brasil, la esquistosomiasis se ha estado difundiendo en forma continuada en función de los movimientos migratorios, al principio por intermedio de personas que habían dejado su lugar de origen en búsqueda de otras regiones que ofrecieran alentadoras perspectivas de colonización. Hoy, en cambio, depende de migrantes que arriban a las ciudades para vivir en áreas periféricas, generalmente carentes de buenas condiciones sanitarias, y para desempeñarse, como mano de obra no especializada, en trabajos vinculados a la construcción, la industria y la agricultura. Así, la presencia de individuos con esquistosomiasis, junto con la de huéspedes intermediarios susceptibles, favorecen la emergencia de nuevos focos.

En el estado de Minas Gerais, las áreas endémicas de esquistosomiasis se localizan al este del río San Francisco, siendo rara su detección en las regiones del oeste, incluida la mesorregión del Alto Paranaíba. Por eso, el objetivo de la reevaluación de la presencia de esquistosomiasis en dicha mesorregión fue verificar la posibilidad de una extensión de la parasitosis a áreas que hasta entonces se consideraban no endémicas. Se capturaron alrededor de cinco caracoles por fuente de agua localizada en las vecindades de las escuelas incluidas en el estudio, y también se obtuvieron de aquellas ubicadas en áreas frecuentadas por los estudiantes. En referencia a la población estudiada, se trató de niños de escuela primaria (7 a 14 años de edad) correspondientes a áreas urbanas de 31 municipios de la región; de cada escolar se obtuvo material fecal para análisis parasitológico.

Un total de 1892 moluscos (género Planorbis) fueron recogidos para su examen: de las seis especies de Biomphalaria identificadas, solo tres (B. glabrata, B. tenagophila y B. straminea) eran epidemiológicamente importantes para la transmisión de esquistosomiasis. Sin embargo, todas las muestras fueron negativas a cercarias de Schistosoma mansoni.

De los 3486 escolares examinados, seis $(0,2 \%)$ fueron positivos a S. mansoni, pero solo uno pudo considerarse autóctono, y correspondió al municipio de Araxá.

En la actualidad, en Brasil se da una aparente paradoja: aunque la quimioterapia a gran escala ha reducido la prevalencia de esquistosomiasis, la enfermedad se está difundiendo a otras áreas, probablemente en función de los movimientos migratorios. En el municipio de Araxá, donde el presente estudio había detectado un único caso autóctono, la esquistosomiasis se introdujo en la década de 1940 como consecuencia de la construcción de un hotel, proyecto que por su envergadura atrajo a migrantes de áreas probablemente infectadas.

Los resultados obtenidos por el estudio permiten establecer que la mesorregión del Alto Paranaíba, con la excepción del municipio de Araxá, está libre de S. mansoni, si bien tanto la presencia de huéspedes intermediarios del parásito como el continuado aflujo de migrantes procedentes de áreas endémicas alertan acerca de su potencial para constituirse en foco de esquistosomiasis. (Carvalho OS, et al. Re-evaluation of schistosomiasis mansoni in Minas Gerais, Brazil - II. Alto Paranaíba mesoregion. Mem Inst Oswaldo Cruz 1997;92:141-142). 